\title{
EFEKTIVITAS FORMULASI SEDIAAN SABUN MANDI PADAT EKSTRAK ETANOL DAUN BELIMBING WULUH (Averrhoa Bilimbi) SEBAGAI PELEMBAB KULIT
}

\author{
Novidawati Boru Situmorang ${ }^{1}$, Dorima Monica Marpaung2, \\ Aminah. $\mathbf{S}^{3}$,Romauli Anna Teresia Marbun ${ }^{4}$ \\ Institut Kesehatan Medistra Lubuk Pakam, Jalan Sudirman No.38 \\ Lubuk Pakam \\ e-mail: novisitumorang95@gmail.com
}

DOI : https://doi.org/10.35451/jfm.v2i2.360

\begin{abstract}
:
Starfruit Leaf (DBW) can be formulated into solid soap bath preparations because based on high antioxidant research it is represented by the content of flavonoids and saponins. The study was conducted to find out that DBW can be formulated into solid bath soap preparations and solid bath coats from Carambola Leaf Ethanol Extract (EEDBW) can moisturize the skin. This study uses an experimental method in which DBW is extracted by maceration. Examination of solid soap preparations carried out in this study were phytochemical screening tests, irritation tests and skin moisture tests by being made with 5 test groups namely concentrations of $2.5 \%, 3.5 \%$ and $4.5 \%$, negative control and positive control (preparations $X$ circulating in the market). Examination using a skin analyzer preparation with a concentration of $4.5 \%$ highest moisturizes the skin that is $52.56 \%$ and does not irritate the skin but physical changes occur after a few days while with a concentration of 3.55 moisturizes the skin $45.53 \%$ is almost equivalent to the positive control circulating on the market. So conclude EEDBW can be formulated into a dense bathing soap preparation and can be used to moisturize the skin.
\end{abstract}

Keywords: Carambola Leaf Extract; Solid Bath Soap; Skin Moisturizer 


\section{PENDAHULUAN}

Indonesia merupakan salah satu negara tropis yang memiliki beragamragam hayati terbesar kedua di dunia. Kawasan hutan tropis Indonesia meliputi 110 juta hektar menyediakan kurang lebih $80 \%$ tumbuhan obat yang terdapat di dunia, dengan 28.000 jenis tumbuhan dan lebih dari 7.000 jenis

berbagai masalah kesehatan, jauh sebelum pelayanan kesehatan formal dan obat modern. Sebagian besar masyarakat memanfaatkan tumbuhan sebagai obat tradisional semakin disukai dengan alasan efek samping lebih kecil dari obat yang dibuat secara sintesis dan untuk menjaga kesegaran tubuh. Dalam kegiatan sehari-hari, kulit sering terpapar oleh radikal bebas baik yang dibentuk dari fungsi normal tubuh ataupun diperoleh dari lingkungan seperti paparan sinar UV, paparan asp merokok, paparan polutan udara, peradangan (Rohana O.S, 2013).

Antioksidan adalah senyawa yang menunda auto-oksidasi dengan menghambat pembentukan radikal bebas atau dengan mengganggu propagasi dari radikal bebas melalui satu atau lebih mekanisme, salah satunya dengan menghambat pembentukan peroksida melalui peredaman radikal bebas. Radikal bebas dapat menyebabkan kerusakan oksidatif yang berfungsi dalam proses penuaan serta menyebabkan penyakit degeneratif yang tampak pada kulit (Heyne, 2011). Secara alami tubuh diperlengkapi dengan antioksidan, dimana fungsinya masih belum sempurna sehingga diperlukan suplementasi antioksidan untuk mengurangi efek kumulatif dari kerusakan oksidatif. Antioksidan topikal diperlukan untuk melindungi diantaranya tumbuhan obat, atau setara dengan $90 \%$ jumlah tumbuhan obat yang dikenal di Asia. Sejauh ini 1.000 jenis diantaranya telah dikenal serta dimanfaatkan secara luas sebagai obat tradisional (Pramono, 2012).

Masyarakat Indonesia banyak menggunakan tumbuhan berkhasiat untuk pengobat dan menanggulangi kulit dan menormalkan kondisi kulit (Heyne, 2011).

Secara umum manusia itu sendiri perlu menjaga kebersihan diri agar tubuh tetap sehat, serta tidak menyebarkan kotoran dan tidak menularkan penyakit. Salah satu langkah dalam pemeliharaan kebersihan antara lain dengan mandi yang teratur menggunakan sabun (Tranggon, 2017).

Sabun mandi yang mengandung senyawa Natrium dengan asam lemak dapat digunakan sebagai pembersih tubuh, baik berbentukpadat, cair dengan atau penambahan lain serta tidak menyebabkan iritasi pada kulit dan berbusa. Syarat mutu sabun mandi padat yang ditetapkan oleh SNI yaitu sabun padat memiliki kadar air maksimal $15 \%$, dengan jumlah alkali bebas maksimal $0,1 \%$ serta jumlah asam lemak kurang dari 2,5\%. Kebanyakan masyarakat sangat meminati sabun antibakteri karena dipercaya dapat membersihkan kulit, dapat mengobati atau mencegah penyakit Cavitch, 2016).

Kemampuan sabun untuk mengangkat kotoran sampai sisa-sisa kosmetik yang menempel di kulit, dikarenakan dalam formulasi sabun mandi terdapat banyak bahan tambahan salah satunya surfaktan yang ditambahkan untuk menurunkan tegangan permukaan saat pembuatan 
sabun, hal ini disetujui karena memiliki gugus hidrofilik dan lipofilik sekaligus dalam satu struktur molekul. Sifat unik ini membuat surfaktan dapat digunakan sebagai bahan pembasah, pengemulsi dan pembusa (Sinatrya, 2012).

Banyaknya busa yang dihasilkan bukan merupakan ukuran standar mutu sabun, namun akan meningkatkan kenyamanan pada penggunaan sabun mandi tersebut. Salah satu surfaktan yang tidak mengiritasi kulit adalah kokamidopropil betain dimana bila dibandingkan dengan natrium lauril sulfat dalam konsentrasi tinggi dapat meningkatkan kelembaban kulit lebih baik (Pranomo, 2012).

Banyak jenis tumbuhan yang dapat digunakan sebagai obat tradisonal, salah satunya adalah belimbing wuluh (Averrhoa Bilimbi Linn). Dimana EDBW mengandung metabolit sekunder seperti (flavonoid, saponin, triterpenoid, tanin , Tanin) serta daun juga mengandung mineral dan vitamin $C$ yang baik untuk kesehatan serta mengatasi berbagai macam masalah kesehatan seperti mengatasi sariawan, jerawat, sakit gigi, rematik, batuk, antikanker, antibakteri, menjaga daya tahan tubuh dan mengobati gatal-gatal pada kulit (Ummah, 2010).

Berdasarkan uraian diatas peneliti tertarik untuk membuat sabun mandi padat yang diformulasi dari EEDBW sebagai pelembab kulit.

\section{METODE}

Penelitian ini mengggunaka metode penelitian Quasi Eksperimental dengan one grup pre and post. Penelitian dilakukan sendiri dengan mengikuti suatu proses, mengamati, menganalisis dan membuat suatu kesimpulan tentang formulasi sediaan sabun mandi padat ekstrak etanol pada daun belimbing wuluh (Averrhoa Bilimbi) sebagai pelembab kulit.

Tempat penelitian ini dilakukan di Laboratorium Farmasi Program Studi Farmasi Institut Kesehatan MEDISTRA Lubuk Pakam. Alat yang digunakan dalam penelitian ini seperti cawan penguap, corong, gelas ukur, kertas saring, neraca analitik, spatula, tabung reaksi, rak tabung reaksi, pipet tetes dan rotary evaporator dan bahan yang digunakan daun belimbing wuluh, etanol $70 \%$, Asam stearat 8 gram, Aquades ad $100 \mathrm{~mL}$, Gliserin $10 \mathrm{~mL}$, Minyak zaitun 8 $\mathrm{mL}, \mathrm{NaOH} 10 \%$, Texapon $6 \mathrm{~mL}$ dan TEA $15 \mathrm{Ml}$.

\section{HASIL DAN PEMBAHASAN}

Hasil Skrining dan Ekstraksi Daun Belimbing Wuluh didapat dari proses skrining fitokimia dapat dilihat pada Tabel 1.

Tabel 1. Hasil Uji Skrining Fitokimia

\begin{tabular}{ccc} 
No & $\begin{array}{c}\text { Ekstraksi Daun } \\
\text { Bilimbing } \\
\text { Wuluh }\end{array}$ & Keterangan \\
\hline 1 & Flavonoid & $\begin{array}{c}(+) \text { Jingga } \\
(+) \text { Buih tidak } \\
\text { hilang }\end{array}$ \\
\hline
\end{tabular}

Sedangkan hasil ekstraksi dari 500 $\mathrm{ml}$ daun belimbing wuluh dengan menggunakan pelarut etanol $70 \%$ yang dipekatkan dengan rotary evaporator pada suhu $\pm 78{ }^{\circ} \mathrm{C}$ yaitu berupa ekstrak $150 \mathrm{ml}$.

Hasil Uji Iritasi Terhadap Responden

Uji ini dilakukan untuk mengetahui ada tidaknya efek samping tersebut maka dilakukan uji iritasi terhadap kulit. Berdasarkan penelitian yang dilakukan maka diperoleh hasil sebagaimana pada Tabel 2.

Tabel 2. Data Uji Iritasi Pada Sukarelawan

$\begin{array}{ll}\text { N Uji iritasi } & \text { Responden }\end{array}$




\begin{tabular}{cccccccccccc}
\hline $\mathbf{0}$ & & $\mathbf{1}$ & $\mathbf{2}$ & $\mathbf{3}$ & $\mathbf{4}$ & $\mathbf{5}$ & $\mathbf{6}$ & $\mathbf{7}$ & $\mathbf{8}$ & $\mathbf{9}$ & $\mathbf{1}$ \\
& & & & & & & & & & & $\mathbf{0}$ \\
\hline 1 & Kemerahan & - & - & - & - & - & - & - & - & - & - \\
2 & Gatal & - & - & - & - & - & - & - & - & - & - \\
3 & Kasar & - & - & - & - & - & - & - & - & - & - \\
\hline
\end{tabular}

Uji iritasi ini dilakukan dengan cara mengoleskan sabun pada lengan bawah atau belakang telinga kemudian dibiarkan selama \pm 1 jam dan dilihat perubahan yang terjadi berupa kemerahan, gatal, kasar, panas dan kering. Dari data tabel diatas tidak terlihat adanya efek samping berupa kemerahan, gatal, kasar, panas, dan kering pada kulit yang ditimbulkan oleh sediaan. Maka dapat disimpulkan sediaan sabun mandi padat dari EEDBW tidak menyebabkan iritasi pada kulit.

Hasil Uji Kesukaan Terhadap Formulasi

Hasil Uji kesukaan responden terhadap sediaan formulasi sabun padat yang dibuat dari bahan EEDBW dari 10 reponden dapat dilihat pada Tabel 3.

Tabel 3. Kesukaan Reponden

\begin{tabular}{ccccc}
\hline $\begin{array}{c}\text { Formula } \\
\text { Sabun }\end{array}$ & \multicolumn{4}{c}{ Skala Kesukaan } \\
\cline { 2 - 5 } & $\begin{array}{c}\text { Sangat } \\
\text { Suka }\end{array}$ & Suka & $\begin{array}{c}\text { Kurang } \\
\text { Suka }\end{array}$ & $\begin{array}{c}\text { Tidak } \\
\text { Suka }\end{array}$ \\
\hline $\begin{array}{c}\text { Formula } \\
2,5 \%\end{array}$ & 3 & 4 & 3 & - \\
$\begin{array}{c}\text { Formula } \\
3,5 \%\end{array}$ & 4 & 5 & 1 & - \\
$\begin{array}{c}\text { Formula } \\
4,5 \%\end{array}$ & 5 & 3 & 2 & - \\
\hline
\end{tabular}

Berdasarkan tabel uji kesukaan diatas menunjukan bahwa formula 4,5\% yang sangat disukai oleh responden kemungkinana hal ini terjadi karena formula 4,5\% memiliki warna dan aroma yang sangat peka dibandingka dengan formula 2,5\% dan 3,5\%, namun setelah penyimpanan beberapa lama terjadi perubahan fisik pada sediaan.

Hasil Uji Kelembapan Sabun

Pengujian kemampuan sediaan untuk melembabkan kulit dilakukan pada 10 orang responden dengan menggunakan alat Skin Moisture Analyzer dengan mengukur persen kelembapan kulit setelah menggunakan sediaan sabun mandi padat ekstrak etanol daun belimbing wuluh berbagai kosentrasi, kontrol positif (KP) dan blanko data yang diperoleh dapat dilihat pada Tabel 4 dan 5.

Tabel 4. Data Hasil Pengukuran

\begin{tabular}{|c|c|c|c|c|c|c|}
\hline \multirow{2}{*}{ No } & \multirow{2}{*}{$\begin{array}{l}\text { Res } \\
\text { pon } \\
\text { den }\end{array}$} & \multicolumn{5}{|c|}{$\begin{array}{c}\text { Data Pengukuruan Persen } \\
\text { Kelembapan Kulit Setelah } \\
\text { Pengolesan Sediaan }\end{array}$} \\
\hline & & $\begin{array}{l}\text { Blan } \\
\text { ko\% }\end{array}$ & $\begin{array}{l}\text { Kp } \\
\%\end{array}$ & $\begin{array}{l}\text { A. } \\
2,5 \\
\%\end{array}$ & $\begin{array}{l}\text { B. } \\
3,5 \\
\%\end{array}$ & $\begin{array}{l}\text { C. } \\
4,5 \\
\%\end{array}$ \\
\hline 1 & I & 36,5 & $\begin{array}{c}59 \\
4\end{array}$ & $\begin{array}{c}40, \\
7\end{array}$ & $\begin{array}{c}47 \\
2\end{array}$ & $\begin{array}{c}50, \\
1\end{array}$ \\
\hline 2 & II & 47,6 & $\begin{array}{c}60 \\
1\end{array}$ & $\begin{array}{c}45, \\
1\end{array}$ & $\begin{array}{c}49 \\
1\end{array}$ & $\begin{array}{c}51, \\
3\end{array}$ \\
\hline 3 & III & 36,2 & $\begin{array}{c}63 \\
5\end{array}$ & $\begin{array}{c}46 \\
6\end{array}$ & $\begin{array}{c}48 \\
3\end{array}$ & $\begin{array}{c}49 \\
8\end{array}$ \\
\hline 4 & IV & 37,7 & $\begin{array}{c}59, \\
5\end{array}$ & $\begin{array}{c}42, \\
5\end{array}$ & $\begin{array}{c}47 \\
1\end{array}$ & $\begin{array}{c}52 \\
2\end{array}$ \\
\hline 5 & V & 38,1 & $\begin{array}{c}58, \\
6\end{array}$ & $\begin{array}{c}43 \\
5\end{array}$ & $\begin{array}{c}48 \\
2\end{array}$ & $\begin{array}{c}54, \\
2\end{array}$ \\
\hline 6 & VI & 34,5 & $\begin{array}{c}58 \\
7\end{array}$ & $\begin{array}{c}42, \\
6\end{array}$ & $\begin{array}{c}49 \\
1\end{array}$ & $\begin{array}{c}53 \\
5\end{array}$ \\
\hline 7 & VII & 35,5 & $\begin{array}{c}60 \\
5\end{array}$ & $\begin{array}{c}45 \\
2\end{array}$ & $\begin{array}{c}48 \\
2\end{array}$ & $\begin{array}{c}52, \\
6\end{array}$ \\
\hline 8 & VIII & 32,5 & $\begin{array}{c}57 \\
5\end{array}$ & $\begin{array}{c}43 \\
6\end{array}$ & $\begin{array}{c}47 \\
8\end{array}$ & $\begin{array}{c}55 \\
6\end{array}$ \\
\hline 9 & IX & 37,1 & $\begin{array}{c}60 \\
5\end{array}$ & $\begin{array}{c}46, \\
5\end{array}$ & $\begin{array}{c}49 \\
0\end{array}$ & $\begin{array}{c}52 \\
9\end{array}$ \\
\hline 10 & $x$ & 35,2 & $\begin{array}{c}59 \\
7\end{array}$ & $\begin{array}{c}59, \\
0\end{array}$ & $\begin{array}{c}48, \\
7\end{array}$ & $\begin{array}{c}53 \\
4\end{array}$ \\
\hline Rat & ata & 37,0 & $\begin{array}{c}59, \\
8\end{array}$ & $\begin{array}{c}45, \\
5\end{array}$ & $\begin{array}{c}48, \\
2\end{array}$ & $\begin{array}{c}52 \\
5\end{array}$ \\
\hline
\end{tabular}

Tabel 5. Rata-rata persen (\%) kelembapan kulit setelah pengolesan sediaan

\begin{tabular}{|c|c|c|c|}
\hline No & Formula & $\begin{array}{c}\text { Rata- } \\
\text { rata } \\
\%\end{array}$ & Hasil \\
\hline 1 & Kontrol positif & 59,8 & Lembab \\
\hline 2 & Blanko & 37,0 & $\begin{array}{l}\text { Kurang } \\
\text { lembab }\end{array}$ \\
\hline 3 & $\begin{array}{l}\text { SSEEDBW } \\
2,5 \%\end{array}$ & 45,5 & Lembab \\
\hline 4 & $\begin{array}{l}\text { SSEEDBW } \\
3,5 \%\end{array}$ & 48,2 & Lembab \\
\hline 5 & $\begin{array}{l}\text { SSEEDBW } \\
4,5 \%\end{array}$ & 52,5 & Lembab \\
\hline
\end{tabular}

Berdasarkan tabel 4 dan 5 diatas dapat dilihat bahwa semakin tinggi kosentrasi esktrak daun belimbing wuluh yang ditambahkan pada sediaan sabun, maka semakin tinggi pula kemampuan untuk melembabkan kulit, hal ini terlihat pada formula $\mathrm{C}$ dengan konsentrasi $4,5 \%$ yang lebih banyak mengandung ekstrak daun belimbing wuluh, dimana ekstrak daun belimbing wuluh terdapat senyawa yang berfungsi untuk melembabkan kulit. Pada formula blanko tidak memberikan efek kelembapan kulit 
setelah pemakain formulasi blanko Karena tidak mengandung zat aktif pada sediaan. Berdasarkan hasil uji kelembapan diketahui bahwa formulasi kontrol positif memberi efek kelembapan yang hampir sama dengan konsentrasi $4,5 \%$.

Menurut referensi dari alat Skin Moisture Analyzer, kriteria kelembaban kulit adalah jika lebih kecil dari $40 \%$ kurang lembab, 40-60\% lembab, dan lebih besar dari $60 \%$ sangat lembab. Berati semua formula dapat melembabkan kulit dengan kategori lembab (Dasar Standardisasi Nasional, 2010).

Hasil Uji pH

Hasil pememeriksaan $\mathrm{pH}$ menunjukkan bahwa sediaan yang dibuat dengan mengunakan EEDBW memiliki pH yang berkisar antara 8,2 $7,2 \mathrm{pH}$ terlihat pada tabel 6 . Ini mendekati $\mathrm{pH}$ fisiologi kulit tubuh yaitu $5,2-6,2 \mathrm{pH}$. Dengan demikian formula ekstrak etanol daun belimbing wuluh dapat digunakan untuk sediaan sabun.

Tabel 6. Hasil Uji pH

\begin{tabular}{cc}
\hline Sediaan & Ph \\
\hline Formula $2,5 \%$ & 8,2 \\
Formula $3,5 \%$ & 7,8 \\
Formula $4,5 \%$ & 7,2
\end{tabular}

\section{SIMPULAN DAN SARAN Simpulan}

Sediaan sabun mandi padat dari ekstrak daun belimbing wuluh mempunyai kemampuan untuk melembabkan kulit, dan yang paling besar di peroleh pada konsentrasi 4,5\% dengan kelembapan 52,56 \% dapat melembabkan kulit dan tidak mengiritasi kulit dan pada konsentrasi 3,5\% dengan kelembapan $48,27 \%$ juga dapat melembabkan kulit tetapi dengan tingkat kelembapan yang sedang, dan pada formulasi $2,5 \%$ dengan kelembapan $45,53 \%$ juga dapat melembabkan kulit tetapi dengan tingkat kelembapan yang lebih rendah

\section{Saran}

Untuk penelitian selajutnya agar dapat membuat sediaan sabun mandi dari ekstrak etanol daun belimbing wuluh (Averrhoa Belimbi) dalam bentuk sediaan lain seperti sabun cair, lotion, sabun transparan, lulur, krim dan sebagainya.

\section{DAFTAR PUSTAKA}

\section{Buku :}

Tranggon,R.I.S., 2017. Buku Pengangan Ilmu Pengetahun Kosmetik. PT Granmedia Indonesia. Jakarta

Heinrich, M., 2009. Farakognosis dan Fisioterapi, Buku Kedokteran Indonesia, Jakarta.

Pranomo, 2012. Atlas Tumbuhan Obat Indonesia. Setiawan Dalimartha Publication. Jakarta

\section{Jurnal :}

Dasar Standardisasi Nasional, 2010. Standar Mutu Sabun Mandi Padat, SNI 06-3532-2010, Defartemen Perindustrian Nasional, Jakarta.

Rohana,O.S, 2013. Karakterisasi Simplisia,Skrining Fitokimia dan Uji AktivitasAntibakteri Ekstrak Etanol Tumbuhan"Rosela" (Hibiscus sabdariffa L.)Terhadap Staphylococcus aureus danEsherichia coli [Skripsi]. Medan: Program Ekstensi Sarjana Farmasi USU.

Sinatriya, 2012. Membuat Sabun Transparan Untuk Gift dan Kecantikan. Penebar Plus. Jakarta.

\section{Artikel Online :}

Cavitch 2016. Isolasi dan Identifikasi Senyawa Anti Mikroba dari Daun BelimbingWuluhPiperSarmentosum 
Roxb.ExHunter,(online)(http://digili b.ac.id/gdl.phpmod=brows\&op=re ad=mikroba\&q=obat). Diakses 27 Maret 2020).

Heyne, 2011. In Vitro Antibacterial Activity of Averrhoa Bilimbi L. Leaves and Fruits Exstrak, International Journal of Tropical Medicine,(online) diakses 15 September 2020

(http://wwwmedwelljornal fulltext/itm/pdf). 